\title{
Modified Personalized System of Instruction vs Traditional Lecture Method of Instruction Using a Within Design at a Small Liberal Arts College
}

\author{
Robert C. Butler, Jess G. Kohlert, Valerie E. McElrath, Kelci L. Wolfe, Gabriel G. Gross \\ King's College, Wilkes-Barre, USA
}

\begin{abstract}
Traditional lectures used in college might not challenge the brightest students and leave the weaker students behind. PSI (Personalized System of Instruction) is designed to adjust to each students' needs so all students can master material. Numerous studies have supported that PSI may be more effective than traditional lectures (J. A. Kulik, C. C. Kulik, \& Bangert-Downs, 1990). However, standard PSI does not fit a traditional academic calendar. A within subjects design was utilized to assess the effectiveness of a modified PSI designed to fit within a traditional academic calendar. Students in two introductory psychology courses were exposed to both a modified PSI and traditional lecture format. Academic performance and student satisfaction were assessed. Results indicate no significant differences in academic performance, course satisfaction, or motivation between PSI and lecture methods. Furthermore, the use of technological supplements available with PSI did not lead to more satisfaction with PSI. This study suggests that modifying PSI by adding time restraints might be detrimental to its increased effectiveness over traditional lecture. Although our study did not support PSI over traditional lecture overall, when students were forced to select a teaching method, 55.2\% reported that they preferred PSI. Limitations and future directions are discussed.
\end{abstract}

Keywords: PSI (Personalized System of Instruction), lecture, student learning, education

In an educational climate where institutions of higher education compete to attract students while simultaneously being criticized for increasing tuition costs and the diminishing benefits of their services (Rossi \& Novack, 2014), educators are under increased pressure to improve the effectiveness of their instruction (National Commission on Writing, 2004). Although individuals are likely to agree that improving higher education is important, there remain large differences of opinion on how to best accomplish this. Many modifications have been suggested including, but not limited to: decreasing classroom size, increasing hands on activities, utilizing small discussion groups, separating students based on skill level, including enrichment activities, and increasing student-faculty interaction (Buskist, Cush, \& DeGrandpre, 1991; Kuh, Kinzie, Schuh, $\&$ Whitt, 2005). Furthermore, many educators simply assume that traditional lecture methods are the most

Robert C. Butler, Ph.D., Department of Psychology, King's College.

Jess G. Kohlert, Ph.D., Department of Psychology, King's College.

Valerie E. McElrath, B.A., Department of Psychology, King's College.

Kelci L. Wolfe, B.A., Department of Psychology, King's College.

Gabriel G. Gross, B.A., Department of Psychology, King's College. 
effective way to educate students, despite resources that suggest this might not be the case (Buskist, Cush, \& DeGrandpre, 1991; Ediger, 2001; J. P. Murry \& J. I. Murry, 1992). As instructors evaluate how to best improve education, one of the central problems is that students enter the classroom with varying skill levels and differing aptitudes for learning (Carver, 1974). This wide variety of learners makes it difficult for educators to apply general adjustments to their teaching styles that also address the individual needs of learners.

PSI has been suggested as an educational method that takes into account the individual differences of learners (Buskist et al., 1991). PSI has its origins in the works of Carroll (1963), Keller (1968), and Bloom (1971). The central concept of PSI is that any student can succeed if given enough time and support to master material (Keller, 1968). In order to provide students with this support, Bloom (1971) suggested that instruction should include the following elements: organizing concepts and skills into learning units, using assessment to educate learners, giving students corrective feedback, providing students with individualized enrichment activities to further learning and understanding, and ensuring that students have mastered a topic before proceeding to the next learning unit. This teaching style allows instructors to make major adjustments for individual students, allows students multiple opportunities to master topics, and can close the achievement gap for individuals who would be left behind in a traditional lecture type setting (Bloom, 1971; 1976).

Multiple applications and adaptations of the basic tenants of PSI have been successfully implemented in a variety of educational settings (Kulik et al., 1990; Zimmerman \& DiBenedetto, 2008). For example, PSI has been effective with various age groups (Guskey \& Gates, 1986; Zimmerman \& DiBenedetto, 2008), special needs groups (Carver, 1974; Zencius, Davis, \& Cuvo, 1990), across disciplines (Kulik, 1976), and with various classroom sizes. Furthermore, PSI permits gifted students to proceed at faster rates than traditional lecture (Sternberg, 1994) and can be used effectively for online learners (Svenningsen \& Pear, 2011). Not only has PSI been adapted to many different settings with many different individuals, but the gains over traditional lecture methods appear to be sizeable. A meta-analysis suggested that students in these programs were able to raise their final test scores 0.5 standard deviations or from the 50th to the 70th percentile (Kulik et al., 1990). This includes both end of the course and long term follow-up assessment.

Despite strong empirical support for PSI and similar educational techniques, traditional lecture methods still persist as the primary form of education in secondary schools (Fox, 2013). There are many plausible explanations that can explain why this modality of teaching has not become more popular. One limitation of PSI is that it requires the educator to reform many of their current teaching practices and they are not aware of how to implement this type of course (Grant \& Spencer, 2003). Additionally, PSI can engender/permit procrastination and hinder the progress of students with less motivation (Heward \& Dunne, 1993). There are many misconceptions about what PSI is and how to apply it, leading to poor implementation, and possible avoidance by educators (Fox, 2013). The additional effort required from educators to implement a PSI class may limit its feasibility (Ainsworth, 1979). For example, one instructor using a traditional lecture style could feasibly provide services for hundreds of students concurrently, but only be able to teach a small fraction of those students if required to personalize instruction for each student. Finally, and perhaps most importantly, the self-paced nature of PSI does not fit a traditional academic calendar due to the mastery criterion (Fox, 2013). The centrality of self-pacing and mastery components have been strongly debated. Frequently programs that followed many components of PSI, but neglected self-pacing and mastery, were not considered part of PSI (Eyre, 2007). 
Given the detriments of the PSI system, it is not surprising that the popularity of PSI significantly decreased between the early 1990's and 2006 (Eyre, 2007). However, with advances in technology and the increased popularity of internet based education there has been a renewed interest in PSI (Eyre, 2007). Not only does the increase in technology make PSI more attractive for non-traditional learning settings that are not constrained by an academic calendar, but it makes implementing PSI in the traditional classroom much more feasible. For example, providing the student with a plethora of additional resources, information, and examples on any unit is much easier with improvements in technology. It is possible that current approaches to PSI incorporating the use of extensive technology aides might be able to adjust the self-pacing and mastery criteria sufficiently to facilitate the standard academic year without hindering the effectiveness for students. Students could have access to a large quantity of relevant information without needing access to the instructor. This could expedite the learning process and make it plausible for even slower learners to master material in a set amount of time.

In addition to addressing questions of effectiveness and feasibility, institutes of higher education must also assess the satisfaction of students with the educational process (Ziaee, Ahmadinejad, \& Morravedji, 2004). Unlike primary education, which can be viewed as having a captive audience, institutions of higher education run the likelihood of losing students to other institutions if their students find the educational process ineffective or aversive (Crosling, Heagney, \& Thomas, 2009). This can jeopardize the fiscal health of the university, and must be taken into consideration when making teaching modifications.

Research supports that students were more satisfied with the PSI method and had more positive views of the information being learned as compared to students in traditional classroom structures. A meta-analysis of 14 studies focusing on students' feelings toward course content being learned under PSI programs versus traditional lecture found that the majority of studies established that students preferred PSI over traditional lecture (Kulik et al., 1990). Similarly, studies by Guskey and Gates $(1986 ; 2010)$ illustrate that students who learned a subject in a PSI course liked the subject more, were more confident in their abilities to achieve, and believed the topic was more important in comparison to students in traditional lecture courses.

PSI has also been found to enhance student's intrinsic motivation and confidence. This increase in confidence increases students' ability to persist in learning (Johnson, Wambugu, \& Wachanga, 2011; Zimmerman \& Dibenedetto, 2008). Motivation is an important element for the academic success of students. Research has found that when students are motivated they accomplish at higher levels and require less corrective time as they advanced through the PSI course units compared to students in conventional classes (Johnson et al., 2011). PSI students also retained information longer and reported more affirmative attitudes in regards to their learning ability compared to students in traditional methods (Guskey \& Gates, 1986).

Although there is an extensive body of research on the effectiveness of PSI, there are limitations to this research. Taken as a whole, research and implementation studies covering the effects of PSI programs have been comparable in design. Researchers have generally used a between subjects design which compared students from PSI with students from traditional lecture courses. Although between subject designs are beneficial to understand a topic, they can introduce methodological issues which impact the results. For example, PSI research has been criticized for its tendency to fail to control for effectiveness of the instructor. Specifically, J. G. Martinez and N. C. Martinez (1988) found that $88 \%$ of the studies they reviewed did not control for instructor effectiveness. Therefore, it is possible that PSI courses are found to be more effective simply because more accomplished instructors are using PSI. J. A. Kulik, C. C. Kulik, and Cohen (1979) found 
support for this hypothesis in their meta-analysis. However, it should be noted that this was not replicated in a later meta-analysis (Kulik et al., 1990). Given the homogeneity of research designs, future research may want to expand our knowledge of PSI by using alternative designs. One such alternative design is within subjects designs. The within subjects design permits students to compare PSI to traditional lecture directly and can easily control for effectiveness of instructor.

Given the pressure on instructors to improve educational practices (Rossi \& Novak, 2014), the large body of research that supports the efficacy of PSI (Fox, 2013), and advances in technology (Chase, 2006) institutions of higher education would be wise to contemplate and explore the possibility of utilizing PSI (Eyre, 2007). However, as addressed above, PSI has limitations, including not fitting the traditional academic calendar, and the homogenous nature of research studies. Therefore, this study evaluates a modified version of PSI for a collegiate level Introduction to Psychology course. Specifically, we modified PSI to fit the traditional academic calendar, incorporated a plethora of internet-based resources, and utilized a within subjects design. We assessed three areas of the course to determine its effectiveness. Specifically, we assessed academic performance, course satisfaction, and motivation. Given the success of PSI, we hypothesized that PSI would outperform the traditional lecture model in all three areas assessed. Additionally, we explored if the degree to which students reported using technology based learning aides predicted the effectiveness of or satisfaction with PSI. We hypothesized that as technology use increased, performance and satisfaction with PSI would also increase.

\section{Method}

We utilized a within subjects design where all participants were exposed to modified PSI and traditional lecture in a college level Introductory Psychology course. Core concepts of PSI identified by Fox (2013) and Pear, Schnerch, Silva, Svenningsen, and Lambert (2011) were used to inform our PSI course. In addition, one of the authors had previously been trained in the PSI method. Although attempts to follow the core concepts of PSI were made, some modifications were required to meet the demands of the academic calendar. To clarify how PSI was utilized, six core conceptsand any modifications are outlined.

Concept One: Information is divided into small manageable units of material. We divided information by chapters, and then further into learning objectives within chapters. Students were assessed on one chapter at a time.

Core Concept Two: Students complete course work at their own pace. We adjusted course pacing by giving students suggested completion dates on a course calendar. The course instructors met with students if they started falling behind the proposed course calendar. Additionally, as suggested by Eyre (2007), students were only permitted to retake a unit exam three times. These modifications helped students complete the course during the restricted time set by the academic calendar. These modifications were further supported by research that suggests that without these modifications, students tend not to study between retesting (Eyre, Parks, \& Crone-Todd, 2006).

Concept Three: Students must master information in one unit before moving onto a new unit. As stated above, students were only given three opportunities to take a unit quiz before proceeding to the next unit. Different authors argue differing criteria for mastery. Subjects in this study were required to achieve an 80 percent on the unit exam or attempt the exam three times before proceeding to the next unit.

Concept Four: Students receive immediate feedback. Students' unit exams were graded immediately following their completion and feedback was given to students. Students were encouraged to ask any questions 
they had to one of two psychology professors who were available. They were also encouraged to review any material they struggled with on the unit examin their textbooks.

Concept Five: Assessments are brief, aligned with learning objectives, and use different versions of the exams to avoid cheating. Unit exams utilized 20 multiple choice questions based on the learning objectives for that chapter. Three versions of each exam were created for each chapter. Attention was made in the creation of exams to ensure that content was similar across all versions.

Concept Six: Students have access to various learning materials including technology based activities. We used the text, Psychology (2nd Edition), by Schacter, Gilbert, and Wegner (2011) for this course. This text was selected specifically because of the extensive online learning aides available for students. These included: an interactive e-book, online videos, virtual laboratory to do experiments, practice quizzes, newsfeeds for relevant developments in the field, study guides, a critical thinking companion, and other aides. In addition to these materials, the instructors created study guides for students that included learning objectives, activities to learn material, additional references for online videos, articles to clarify material, and examples of the material. Students had access to tutors provided through the college. Finally, students were encouraged to meet with and had access to two psychology professors. The two professors were selected for their different expertise. Specifically, one professor has expertise in biological psychology and animal models. The other professor has expertise in clinical psychology and research methods.

\section{Sample and Participant Selection}

The study was conducted at a small liberal arts college that is predominantly Caucasian. Sixty-seven students enrolled in two sections of Introduction to Psychology served as participants. Subjects included 30 males and 37 females. The classes were composed of students at various levels of training. However, the majority of participants were college freshman (70.1\%). All subjects were exposed to PSI and traditional lecture. Specifically, for the first half of the semester one section received traditional lecture while the other section engaged in PSI. Students were given a midterm exam and course satisfaction questionnaire. Following midterm, students who received the traditional lecture then engaged in PSI and vice versa, achieving a within subjects design. Students were given another exam at the end of the course. However, this exam only covered material from the second half of the semester. Students again completed the course satisfaction questionnaire, but were asked to focus on just the second half of the course. We used students' mid-term and final exam scores to assess for academic performance, and compared their test score from the half of the course that they had traditional lecture to the half in which they had PSI. The course satisfaction questionnaire contained 12 questions; four questions assessed to what extent participants felt as if they had learned the material presented in the course, four questions assessed satisfaction, and four questions assessed motivation. All questions on the course evaluations utilized a 7-point Likert-type scale. Participants also reported on what learning resources they used following the PSI condition, including the use of: the textbook, computer based study aides, instructor study guides, and asking instructors questions. Finally, students were given a questionnaire about which teaching modality they preferred.

\section{Results}

Paired-samples $t$-tests revealed no significant difference between PSI and traditional lecture for academic performance $(t(66)<0.01, p=1.00)$, course satisfaction $(t(59)=0.22, p=0.83)$, or motivation $(t(58)=0.32, p$ 
$=0.75$ ). Furthermore, multivariate regression analysis did not find a significant impact of which learning resources (textbook, publishers website, study aides provided by instructors, and using the instructors) students reported using on academic performance $(F(4,54)=1.19, p=0.33)$, course satisfaction $(F(4,54)=0.68, p=$ $0.61)$, or motivation $(F(4,53)=0.78, p=0.54)$ in the PSI condition of the course. These findings suggest that the use of technology did not lead to a more favorable experience with PSI in the sample. When asked to pick between the two course styles, $44.8 \%$ reported preferring traditional lecture and 55.2\% reported preferring PSI.

Table 1

Students Report of Use and Usefulness of Course Learning Materials

\begin{tabular}{lll}
\hline Course learning material & $n$ & Mean $(S D)$ \\
\hline Use & & $5.88(0.81)$ \\
Textbook & 59 & $3.9(2.17)$ \\
Publisher website & 59 & $4.14(1.89)$ \\
Professor's study aides & 59 & $2.92(1.79)$ \\
Asking professors & 59 & \\
Usefulness & & $6.47(0.70)$ \\
Textbook & 59 & $5.48(1.64)$ \\
Publisher website & 46 & $5.17(1.67)$ \\
Professor's study aides & 52 & $5.04(1.47)$ \\
Asking professors & 48 & \\
\hline
\end{tabular}

Notes. Responses were given on a 7 point likert-type scale; Use: $1=$ Never used, 7 = The only thing I used; Usefulness: $1=$ Extremely unhelpful, 7 = Extremely helpful.

\section{Discussion}

Literature suggests that educators are under increased pressure to improve the effectiveness of their instruction (National Commission on Writing, 2004). A major constraint troubling our education system is that students enter the classroom with varying skill levels and differing aptitudes for learning (Carver, 1974). PSI has been suggested as an educational method that takes into account the individual differences of learners (Buskist, Cush, \& DeGrandpre, 1991). A meta-analysis of over 75 comparative studies establishes an overall support of PSI in terms of the production of superior student achievement, less variation in achievement, and higher student ratings in college courses (Kulik et al., 1979). However, central to the PSI method is that students are self-paced and do not proceed to new material until they demonstrate mastery of current material (Carver,1974). Although appealing in many ways, this time line for learning is incompatible with the demands of the academic calendar. In this study, PSI was modified to fit the demands of the academic calendar and utilized a within subjects design to permit direct comparisons. It was found that when PSI was modified, there were no significant differences between students' academic performance, course satisfaction, or motivation in the PSI section of the course in comparison with traditional lecture.

There are several possible explanations for our findings. Foremost, previous research supports that when PSI is modified, its effectiveness decreases (Kulik et al., 1979). Although the modifications to PSI utilized in this study were minimal, it is probable that the modifications to self-pacing and mastery criteria change the central nature of PSI and remove core elements necessary to make it effective. According to Keller (1968), the central concept of PSI is that any student can succeed if given enough time and support to master material. By forcing students to complete this course during the academic calendar, we did not permit the slowest learners in 
the course the time necessary for them to master the material. Even with the increased amount of information available through internet-based resources, we still did not see improved performance on the modified PSI. Given the large body of research that supports the effectiveness of PSI, it appears that the self-paced nature in conjunction with the mastery criteria is necessary for its success. Furthermore, it is plausible that less effective learners do not utilize the additional resources and are not exposed to the information to a greater extent unless the course structure uses the mastery criteria to force a minimal level of exposure and competence. Therefore, it might be a fair interpretation of the data that in order for institutions of higher education to use PSI effectively, rethinking the traditional academic calendar might be necessary. Modifying the traditional academic calendar to be compatible with PSI introduces a plethora of difficulties too extensive to cover in this article. However, some items to consider include the demands on the instructor, demands on the institution, and numerous other questions, such as when does a student fail, or how does or should an institution differentially charge a student who takes a month to complete a course verses a student who takes a year.

When considering the use of PSI at the collegiate level, another consideration is the impact this model would have on the usefulness of GPAs. Although we hope that grades reflect to what extent students have mastered a topic, we also know that grades reflect many other skill sets, such as time management skills, maturity, conscientiousness, and achievement motivation (K. C. William \& C. C. Williams, 2011). All of these skills are beneficial for graduate schools and employers to be aware of. Therefore, when colleges contemplate the adoption of PSI methods, questions of how to accurately portray their students' abilities becomes another concern.

In addition to the problems with modifying the structure of PSI, it is probable that there is a confound between PSI and instructor effects. Specifically, Hursh (1976) reported that it was possible that part of the effectiveness of PSI is an effect of the instructor instead of the method. Specifically, when the same instructor taught both the PSI course and the traditional lecture course, the impact of PSI diminished (Kulik et al., 1979). Therefore, it is possible that finding no significant differences between PSI and traditional lecture in this study was due to our utilization of the same instructors for both the PSI and traditional lecture traditions. If this is the case, and the effectiveness of PSI is largely tied to the effectiveness of the instructor, this has many far reaching implications for the importance of PSI. For example, it has been suggested that due to the time intensive nature of PSI, less trained (and therefore less expensive) instructors could implement PSI. However, the findings of this study in combination with other studies listed in the introduction (Ainsworth, 1979; Grant \& Spencer, 2003; Fox, 2013) suggest that because a skilled instructor is likely necessary for PSI, with the additional time restraints, traditional lecture methods might be more cost effective. Further research on this topic may be merited.

The practicality of PSI for instructors must also be taken into consideration. Although learning outcomes for the PSI and traditional lecture did not differ, the effort made by the instructors was significantly different. A limit of this study was that quantitative data on instructors' efforts was not collected. However, qualitatively, both instructors reported that the PSI condition took significantly more time and effort than the traditional lecture. Other research that has collected data on instructors' effort has confirmed that PSI takes significantly more time (Martinez, 2001). Furthermore, students did not report a significant difference in perception of the effort or dedication of the instructors based on teaching method $(t(59)=0.33, p=0.75)$. Therefore, although instructors may be putting forth much greater efforts for their students in a PSI model, it is probable that they do not see a commensurate payoff in their teaching evaluations. This finding in combination with the lack in 
benefits for students when PSI is modified may partially explain the decrease in popularity of PSI referred to by Eyre (2007).

This study failed to support previous research which showed that students in a PSI based course reported higher levels of motivation than students in a traditional lecture course (Johnson et al., 2011; Zimmerman \& Dibenedetto, 2008). Previous research suggested that when students are able to self-pace and do not have limits on the number of times they can retake an exam they tend to retake exams without further studying (Eyre, Parks, \& Crone-Todd, 2006). This has led to the suggestion that limiting number of attempts for students might actually increase motivation (Eyre et al., 2006). However, our study did not support this. It is interesting to note that although there was not a significant difference in motivation between the PSI and traditional lecture conditions, it does appear that students reported significantly different amounts of motivation from one condition to the next, with many students reporting much stronger or weaker motivation for PSI in comparison to traditional lecture. This supports one of the common pieces of qualitative feedback we received from the students in these courses. Specifically, multiple students wrote that they found either PSI or traditional lecture to be more motivating or more beneficial. This suggests that allowing students to self-select into PSI or traditional lecture may be beneficial. Allowing students to self-select into a teaching style might create the best match between learner and instruction style, and thus maximize student performance and satisfaction. However, given that the bulk of education utilizes traditional lecture methods, it might be unfair to have students self-select into a teaching style without enough knowledge to make an informed decision.

The findings of this study are also informative in helping instructors determine what learning resources to promote with their students. Specifically, we discovered that following the use of the textbook, students relied on teacher provided study aides most followed by the online text book supplements, distantly followed by asking the instructors questions (See Table 1 for a summary). It is possible that due to the nature of the PSI course, students might not feel as comfortable seeking out help from the instructor. Therefore, instructors of PSI courses may want to take extra time to encourage students to seek out help when needed. Additionally, given the excellent online teaching aides being provided by publishers, teachers may want to encourage or even require assignments that help students familiarize themselves with such technology-based aides.

Finally, although our study did not support PSI over traditional lecture overall, when students were forced to select a teaching method they preferred, 55.2\% reported that they preferred PSI. Although only a small percentage, this finding does support the previous literature that students tend to prefer PSI.

\section{Limitations and Future Directions}

As discussed earlier, the within subjects design makes this study unique, and gives different insight into the PSI question than between subjects designs. However, by creating a setting where students were only in the PSI condition for half of a semester, it is possible that students did not get the full benefit of PSI due to the limited time frame. Future studies should evaluate the effectiveness of modified PSI across the entire academic semester. Additionally, this study relied upon qualitative responses by the instructors involved in the study to assess the amount of time put into the two different teaching conditions. Furthermore, no measure of previous experience and comfort with the two teaching methods by the instructors or students were included. Future research would benefit from taking these variables into account.

As reported above, when taken as a whole, there was not a statistical difference between students' preference for PSI and traditional lecture. However, taken individually, students reported strong preferences for 
one teaching methodology over the other. Therefore, it may be beneficial if future studies evaluate the effectiveness of PSI when students are allowed to self-select into this teaching modality.

Another limitation of this study is that despite providing multiple technology-based opportunities to learn, many participants only utilized this materials minimally (see Table 1). Therefore, future research may want to evaluate models that would increase student use of technology. For example, CAPSI (computer-aided personalized system of instruction), is founded on PSI'S design and has proven to be a relatively easy and effective way to implement this method of instruction (Svenningsen \& Pear, 2011). Research is needed to determine if using technology-based PSI is more effectively, and can ameliorate the difficulties of implementing PSI in person. Examples of areas for further exploration include the possibility of CAPSI significantly reducing the amount of time and effort required from the instructor, while permitting large amounts of students to enroll within a single class at once.

\section{Conclusions}

Overall, the findings of this study suggest that modifying PSI decreases its effectiveness for improving academic performance, student motivation, and overall satisfaction. Despite the aforementioned limitations, this study has important implications for educators who are considering the implementation of PSI to improve teaching efficacy. Findings suggest that modifying PSI to fit the academic calendar is problematic, and future researchers may want to evaluate if different modifications can be made to accommodate the academic calendar, or if the academic calendar can be changed to accommodate PSI. There is a plethora of knowledge that can be gained from the PSI research. Future research is needed to explore how to apply the lessons learned from PSI while meeting the demands of both students and the institution.

\section{References}

Ainsworth, L. L. (1979). Self-paced instruction: An innovation that failed. Teaching of Psychology, 6(1), 42-46.

Bloom, B. S. (1971). Mastery learning. In J. H. Block (Ed.), Mastery learning: Theory and practice (pp. 47-63). New York: Holt, Rinehart and Winston.

Bloom, B. S. (1976). Human characteristics and school learning. New York: McGraw-Hill.

Buskist, W., Cush, D., \& DeGrandpre, R. J. (1991). The life and times of PSI. Journal of Behavioral Education, 1(2), $215-234$. doi:10.1007/BF00957005

Carroll, J. B. (1963). A model of school learning. Teachers College Record, 64, 723-733.

Carver, R. P. (1974). Two dimensions of tests: Psychometric and edumetric. American Psychologist, 29, 512-518.

Chase, J. A. (2006). Differential effects of elaborate feedback and basis feedback on student performance in a modified PSI course (Unpublished masters thesis, The University of Nevada, Reno).

Crosling, G., Heagney, M., \& Thomas, L. (2009). Improving student retention in higher education: Improving teaching and learning. Australian Universities' Review, 51(2), 9-18.

Ediger, M. (2001). Learning opportunities in the higher education curriculum. College Student Journal, 35(3), 410.

Eyre, H. L., Parks, K., \& Crone-Todd, D. E. (2006, October). Student unit test persistence in a mastery-based general psychology course. Poster presented at the annual meeting of the Southeastern Association for Behavior Analysis, Greenville, S.C..

Eyre, H. L. (2007). Keller's personalized system of instruction: Was it a fleeting fancy or is there a revival on the horizon. The Behavior Analyst Today, 8(3), 317-324.

Fox, E. J. (2013). Keller's personalized system of instruction. In J. Hattie, \& E. M. Anderman, International guide to student achievement. New York: Routledge.

Grant, L. K., \& Spencer, R. E. (2003). The personalized system of instruction: Review and applications to distance education. International Review of Research in Open and Distance Learning, 4(2), 1-12.

Guskey, T. R., \& Gates, S. L. (1986). Synthesis of research on the effects of mastery learning in elementary and secondary classrooms. Educational Leadership, 43(8), 73-80. 
Guskey, T. R. (2010). Lessons of mastery learning. Interventions That Work, 68(2), 52-57.

Heward, W. L., \& Dunne, J. D. (1993). For students of behavior analysis. The Behavior Analyst, 2, 341-345.

Hursh, D. E. (1976). Personalized systems of instruction: What do the data indicate? Journal of Personalized Instruction, 1(2), 91-105.

Johnson, C. M., Wambugu, P. C., \& Wachanga, S. (2011). Investigations of student' motivation towards learning secondary school physics through mastery learning approach. International Journal of Science and Mathematics Education, 9 , 1333-1350.

Keller, F. S. (1968). “Good-bye, teacher...”. Journal of Applied Behavior Analysis, 1, 79-89.

Kuh, G. D., Kinzie, J., Schuh, J. H., \& Whitt, J. (2005). Student success in college: Creating conditions that matter. San Francisco: Jossey-Bass.

Kulik, C. C., Kulik, J. A., \& Bangert-Drowns, R. L. (1990). Effectiveness of mastery learning programs: A meta-analysis. Review of Educational Research, 60(2), 265-299.

Kulik, J. A. (1976). PSI: A formative evaluation. In B. A. Green, Jr., (Ed.). Personalized instruction in higher education: Proceedings of the second national conference. Washington, D.C.: Center for Personalized Instruction.

Kulik, J. A., Kulik, C. C., \& Cohen, P. A. (1979). A meta-analysis of outcome studies of Keller's personalized system of instruction. American Psychologist, 34(4), 307-318. doi:10.1037/0003-066X.34.4.307

Martinez, M. (2001). Key design considerations for personalized learning on the web. Educational Technology \& Society, 4(1), 26-40.

Martinez, J. G. R., \& Martinez, N. C. (1988). Hello teacher: An argument for re-emphasizing the teacher's role in PSI and master learning. American Journal of Education, 97(1), 356-363.

Murry, J. P., \& Murry, J. I. (1992). How do I lecture thee? College Teaching, 3(40), 109-113.

National Commission on Writing. (2004). Writing a ticket to work... or a ticket out: A survey of business leaders. New York: College Board.

Pear, J. J., Schnerch, G. J., Silva, K. M., Svenningsen, L., \& Lambert, J. (2011). Web-based computer-aided personalized system of instruction. New Directions for Teaching and Learning, 128, 85-94. Doi: 10.1002/t1.471

Rossi, A. (Producer \& Director), \& Novack, K. (Producer). (2014). Ivory Tower (Motion Picture). United States: Participant Media Paramount Pictures Samuel Goldwyn Films.

Schacter, D. L., Gilbert, D. T., \& Wegner, D. M. (2011). Psychology (2nd Edition). New York: Worth.

Sternberg, R. J. (1994). Allowing for thinking styles. Educational Leadership, 52(3), 36-40.

Svenningsen, L., \& Pear, J. J. (2011). Effects of computer-aided personalized system of instruction in developing knowledge and critical thinking in blended learning courses. Behavior Analyst Today, 12(1), 33-39.

William, K. C., \& Williams, C. C. (2011). Five key ingredients for improving student motivation. Research in Higher Education Journal, 26, 104-122.

Zencius, A. H., Davis, P. K., \& Cuvo, A. J. (1990). A personalized system of instruction for teaching checking account skills to adults with mild disabilities. Journal of Applied Behavior Analysis, 2, 245-252.

Ziaee, V., Ahmadinejad, Z., \& Morravedji, A. R. (2004). An evaluation on medical students' satisfaction with clinical education and its effective factors. Medical Education Online, 9(8), 1-8.

Zimmerman, B. J., \& Dibenedetto, M. K. (2008). Mastery learning and assessment: Implications for students and teachers in an era of high-stakes testing. Psychology in the Schools, 45(3), 206-216. doi:10.1002/pits.20291 